\title{
Atrophic Lesion on the Abdomen
}

Chelsea Elizabeth Steele, MD; Dean S. Morrell, MD; Megan Evans, MD

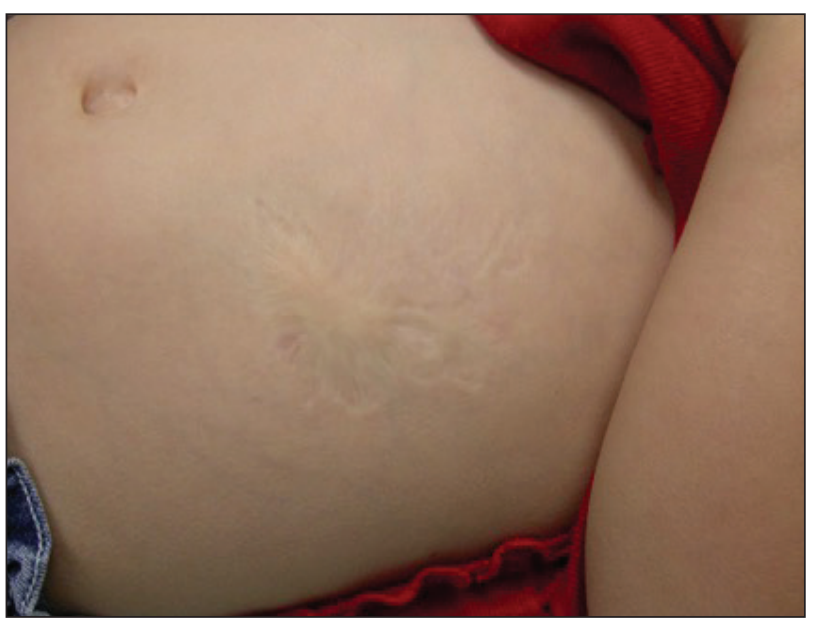

An 18-month-old child presented with a 4-cm, atrophic, flesh-colored plaque on the left lateral aspect of the abdomen with overlying wrinkling of the skin. There was no outpouching of the skin or pain associated with the lesion. No other skin abnormalities were noted. The child was born premature at 30 weeks' gestation (birth weight, $1400 \mathrm{~g})$. The postnatal course was complicated by respiratory distress syndrome requiring prolonged ventilator support. The infant was in the neonatal intensive care unit for 5 months. The atrophic lesion first developed at 5 months of life and remained stable. Although the lesion was not present at birth, the parents noted that it was preceded by an ecchymotic lesion without necrosis that was first noticed at 2 months of life while the patient was in the neonatal intensive care unit.

\section{WHAT'S THE DIAGNOSIS?}
a. anetoderma of prematurity
b. connective tissue nevi
c. cutis laxa
d. focal dermal hypoplasia
e. nevus lipomatosus superficialis 


\section{THE DIAGNOSIS:}

\section{Anetoderma of Prematurity}

$\Lambda$ netoderma is a rare benign cutaneous disorder characterized by atrophic patches of skin due to dermal thinning. The term anetoderma is derived from the Greek words anetos (relaxed) and derma (skin). ${ }^{1}$ The physical appearance of the skin is associated with a reduction or loss of elastic tissue in the dermal layer, as seen on histolopathology. ${ }^{2}$

Two forms of anetoderma have been described. Primary anetoderma is an idiopathic form with no preceding inflammatory lesions. Secondary anetoderma is a reactive process linked to a known preceding inflammatory, infectious, autoimmune, or drug-induced condition. ${ }^{3}$ On histopathology, both primary and secondary anetoderma are characterized by a loss of elastic tissue or elastin fibers in the superficial to mid dermis. ${ }^{2}$

Anetoderma of prematurity was first described in 1996 by Prizant et $\mathrm{al}^{4}$ in 9 extremely premature (24-29 weeks' gestation) infants in neonatal intensive care units (NICUs). Although the exact mechanism behind anetoderma of prematurity is still unknown, Prizant et $\mathrm{al}^{4}$ and other investigators ${ }^{5}$ postulated that application of adhesive monitoring leads in the NICU played a role in the development of the lesions.

Iatrogenic anetoderma of prematurity is clinically characterized by circumscribed areas of either wrinkled macular depression or pouchlike herniations, ranging from flesh-colored to violaceous hues. Lesion size varies from a few millimeters to several centimeters in diameter, and they often are oval or round in shape. ${ }^{2}$ Although not common, it is possible for the atrophic patches to be preceded by an area of ecchymosis without necrosis or atrophy and, if present, they usually evolve within a few days to the characteristic appearance of anetoderma. ${ }^{3}$ They are found at discrete sites where monitoring leads or other medical devices are commonly placed, such as the forehead, abdomen, chest, and proximal limbs.

Lesions of anetoderma of prematurity are not present at birth, which distinguishes them from congenital anetoderma. ${ }^{6}$ It is unclear if the lesions are associated with the degree of prematurity, extremely low birth weight, or other associated factors of preterm birth. Although often clinically diagnosed, the diagnosis can be confirmed by a loss of elastic fibers on histopathology when stained with Verhoeff-van Gieson stain. ${ }^{1}$ Over time, the atrophic patches have the potential to evolve into herniated forms of anetoderma. Self-healing or improvement of the lesions often does not occur. Although the lesion is benign, it often requires surgical correction later in life for cosmesis.

Infants in the NICU are at risk for iatrogenic cutaneous injuries, which rarely may include anetoderma.
Anetoderma of prematurity has been linked to the use of monitoring leads, adhesive tape, and other medical devices placed on the skin. Prizant et $\mathrm{al}^{4}$ postulated that the cause of anetoderma in these infants was irritants such as skin cleansers, urine, or sweat that may be trapped under the electrodes. Other hypotheses include local hypoxemia due to prolonged pressure from the electrodes on immature skin or excessive traction used when removing adhesive tape from the skin. ${ }^{7,8}$ Premature infants may be more susceptible to these lesions because of the reduced epidermal thickness of premature skin; immaturity of skin structure; or functional immaturity of elastin deposition regulators, such as elastase, lysyl oxidase, the complement system, and decayaccelerating factor. ${ }^{3}$ The diagnosis should be differentiated from congenital anetoderma, which also has been described in premature neonates but is characterized by lesions that are present at birth. Its origins are still unclear, despite having histopathologic features similar to iatrogenic anetoderma. ${ }^{9}$

Focal dermal hypoplasia (FDH) is the hallmark cutaneous finding in Goltz syndrome, a rare set of congenital abnormalities of the skin, oral structures, musculoskeletal system, and central nervous system. Similar to congenital anetoderma, FDH also is characterized by atrophic cutaneous lesions; however, the cutaneous lesions in FDH appear as linear, streaky atrophic lesions often with telangiectasias that follow Blaschko lines. ${ }^{10}$ The cutaneous lesions in FDH often are associated with other noncutaneous signs such as polydactyly or asymmetric limbs. ${ }^{10}$ Cutis laxa is caused by an abnormality in the elastic tissue resulting in a loose sagging appearance of the skin and frequently results in an aged facial appearance. There are both acquired and inherited forms that can be either solely cutaneous or present with extracutaneous features, such as cardiac abnormalities or emphysema. ${ }^{11}$

In contrast to the atrophic appearance of anetodermas, connective tissue nevi and nevus lipomatosus superficialis present as hamartomas that either can be present at birth or arise in infancy. Connective tissue nevi are hamartomas of dermal connective tissue that consist of excessive production of collagen, elastin, or glycosaminoglycans and appear as slightly elevated, flesh-colored to yellow nodules or plaques. ${ }^{12}$ Connective tissue nevi often are described in association with other diseases, most commonly tuberous sclerosis (shagreen patches) or familial cutaneous collagenoma. Nevus lipomatosus superficialis is an asymptomatic connective tissue hamartoma composed of mature adipocytes in the dermis. The lesions consist of clusters of flesh-colored to yellow, soft, rubbery papules or nodules with a smooth or verrucoid 
surface that do not cross the midline and may follow Blaschko lines. ${ }^{11}$

With advances in neonatal infant medical care, survival of extremely premature infants is increasing, and it is possible that this rare cutaneous disorder may become more prevalent. Care should be taken to avoid unnecessary pressure on surfaces where electrodes are placed and tightly applied adhesive tape. When electrodes are placed on the ventral side, the child should be placed supine; similarly, place electrodes on the dorsal side when the child is lying prone. ${ }^{5}$ A diagnosis of anetoderma of prematurity later in childhood may be difficult, so knowledge and awareness can help guide pediatricians and dermatologists to a correct diagnosis and prevent unnecessary evaluations and/or concerns.

\section{REFERENCES}

1. Misch KJ, Rhodes EL, Allen J, et al. Anetoderma of Jadassohn. J R Soc Med.1988;81:734-736.

2. Venencie PY, Winkelmann RK. Histopathologic findings in anetoderma. Arch Dermatol. 1984;120:1040-1044.
3. Maffeis L, Pugni L, Pietrasanta C, et al. Case report iatrogenic anetoderma of prematurity: a case report and review of the literature. 2014;2014:781493.

4. Prizant TL, Lucky AW, Frieden IJ, et al. Spontaneous atrophic patches in extremely premature infants: anetoderma of prematurity. Arch Dermatol. 1996;132:671-674.

5. Goujon E, Beer F, Gay S, et al. Anetoderma of prematurity: an iatrogenic consequence of neonatal intensive care anetoderma of prematurity from NICU. Arch Dermatol. 2010;146:565-567.

6. Wain EM, Mellerio JE, Robson A, et al. Congenital anetoderma in a preterm infant. Pediatr Dermatol. 2008;25:626-629.

7. Colditz PB, Dunster KR, Joy GJ, et al. Anetoderma of prematurity in association with electrocardiographic electrodes. J Am Acad Dermatol. 1999;41:479-481.

8. Goujan E, Beer F, Gay S, et al. Study supervision. Arch Dermatol. 2010;146:565-567.

9. Aberer E, Weissenbacher G. Congenital anetoderma induced by intrauterine infection? Arch Dermatol. 1997;133:526-527.

10. Mallory SB, Krafchik BR, Moore DJ, et al. Goltz syndrome. Pediatr Dermatol. 1989;6:251-253.

11. Bolognia J, Schaffer J, Cerroni L. Dermatology. Elsevier Saunders; 2017.

12. Uitto J, Santa Cruz DJ, Eisen AZ. Connective tissue nevi of the skin. clinical, genetic, and histopathologic classification of hamartomas of the collagen, elastin, and proteoglycan type. J Am Acad Dermatol. 1980;3:441-461. 